\title{
Interactive and Interdisciplinary Student Work: A Facilitative Methodology to Encourage Lifelong Learning
}

\author{
Jennie Blake \\ University of Manchester \\ jennifer.blake@manchester.ac.uk \\ Sam Illingworth \\ Manchester Metropolitan University \\ s.illingworth@mmu.ac.uk
}

\begin{abstract}
In order to support and facilitate continuous learning and a growth mindset, it is essential that students be exposed to learning opportunities that explicitly allow them to apply and practice what they have learned. (Dweck, 2007)This paper focuses on one such approach, taken in the My Learning Essentials skills support programme developed at the University of Manchester. This programme rests on a constructivist and collectivist approach that requires student engagement in the creation of learning opportunities and thus encourages students to apply what they have learned to a wide variety of opportunities and assessments, pushing the response to feedback or to an identified skills gap from specific assignments to skill progression and personal development. In addition, the facilitators of such sessions are also freed from the role of "expert" and instead act as knowledge builders with the rest of the group. This change removes the possibility of one "correct" answer and the assumption of eventual perfection and instead encourages the entire group to focus on understanding the process and progressing both within the session and beyond. Although there are still a number of questions to be answered, initial feedback and investigations support the assertions that students engagement in the creation of such opportunities leads to a clearer understanding of the efficacy of the skills involved and the power of the prior knowledge of the community.
\end{abstract}

Keywords: Lifelong learning, facilitation, skills support, academic skills

\section{Introduction}

Frank Smith's To Think states,

Like remembering, understanding is easy when it is not a particular focus of attention, when we are engaged in something that is interesting, meaningful, and natural to us, when the brain is in charge, 
pursuing its own purposes in the light of its own experience (2014: 36-37).

In these situations, the older 'transmissive' model of learning does students a disservice, assuming that they are mere receptacles to be filled with the expertise and curated knowledge of the instructor (Jonassen and Land, 2012). This model not only requires that the student submit to the experience of the teacher, but also puts the trainer in the position of being entirely responsible for the content and learning taking place (see e.g. Marjanovic and Bandara, 2011). This model, the teacher as leader and expert, limits the transmission of knowledge to a one-way discourse, with the majority of the power to shape content and experience in the hands of the lecturer/expert. Instead, constructivist and learner-centred learning puts the focus on the learner as co-creator and lessens the demand on the teacher to act as an expert with all possible answers and all necessary information.

The basic premise of lifelong learning is that people need to continually enhance their understanding and expertise, beyond that which is provided for in a formal learning environment. Whilst there are many definitions of lifelong learning, this paper takes the approach adopted by Sharples (2000: 178), in characterising lifelong learning 'as an extended and holistic process of developing skills and understanding.' In order for lifelong learning to be effective, it is important that the responsibilities and values of the learners are incorporated into the learning experience (Collins, 2004), with expectations for lifelong learning favouring a type of instruction that encourages learners as active participants (Huang, 2002). Ultimately, there should be an increase in learner autonomy, and a movement away from the one-way discourse (Goodyear, 2000) towards a more constructivist and learner-centred learning environment.

The University of Manchester's Alan Gilbert Learning Commons was specifically designed to act as a hub for the sort of interactive learning experience that invites the participants to contribute on an equal footing with the trainer to the development of the final product. Deliberately designed to encourage group work and student interaction, the building carefully incorporates the student voice through student-created art, student consultation on the design of the learning spaces, and a clear remit to support the students in their learning at the University (Jones and Blake, 2013). The Learning Commons focuses on flexible learning spaces, encouraging students to create the space they need for their own learning by shifting furniture, consulting on new initiatives to support their learning, and defining the rules and procedures for the building and its contents. Over 60,000 people entered the building in its first month of opening, with the $1000+$ flexible study spaces in constant demand throughout the academic year (Jones, 2013). The Learning Commons also supports a large number of postgraduate and mature students, and is also available for use by members of staff from across the University. To make lifelong learning an important 
part of human life, new and stimulating physical and intellectual spaces need to be created (Fischer, 1999), which can encourage lifelong learning to take place, and stimulate its pursuit. The Learning Commons can be defined as one of these spaces, allowing groups and individuals to explore alternative ways of learning.

The Learning Commons is naturally seen as a hub for student activity. Its central location on campus allows it to function as a support provider and to signpost students and staff to other resources available across the University. In addition to being open $24 / 7$ during term time, the Learning Commons is a bookless library site, and thus must highlight and acknowledge the value of what the patrons bring in with them. It also emphasises that the learning that goes on must incorporate the priorknowledge and input of those participating in it. This means that any support that is provided must also be able to shape itself to its participants, to deliver what they need when they need it. The training room that sits in the building supports the focus on interactive and learner-centred learning, with moveable furniture and a bank of laptops, allowing for maximum flexibility and approaches to learning. This focus on support and flexibility, are keys to the building and have been built into the methodology and structure of the library's newest skills support programme, the 'My Learning Essentials' (MLE) open training programme.

My Learning Essentials focuses on skills support for the students and staff in an interactive and innovative manner. Student consultation informed its creation, through a separate research project conducted prior to the completion of the Learning Commons, which focused on the use of resources available at the University of Manchester. That research project, titled 'HEARing Student Voices', highlighted the need for a centralised and student-selecting skills support programme, one where students (and staff) could seek out the help they needed at the time they needed it - and one that would allow them to make the crucial steps to understanding how to improve skills and utilise feedback (Blake et al., 2010). At the time of this study, students described their struggles to access what resources were available, and often found them useful only in the specific instance they were delivered - instead of being able to incorporate what they had learned in order to improve a broad set of skills. This made it difficult for students to truly take advantage of the learning opportunities available to them and discouraged further seeking of support or effort (Blake et al., 2010).

Effectively, the students were often approaching the resources previously available with a fixed mindset, unwilling to make an attempt to learn a new skill or seek help because of a fear of being judged and a lack of confidence in the worth of effort. A fixed mindset, as defined by Carol Dweck, is one that tends to create a learning experience that feels stressful and judgemental, one where mistakes and 'failure' (and the learning the comes with them) must be avoided at all costs (Dweck, 2006). This mindset stalls 
the learning process by assuming that there is little purpose in focusing on specific improvements, as it is unlikely to change one's abilities, preventing learners from seeing the next steps that could be taken to improve, or from even seeing that improvement was possible. In addition, it encourages learners to think of mistakes as permanent failures with little hope for improvement.

Meaningful work not only promotes learning in the immediate situation, but also promotes a love of learning and resilience in the face of obstacles (Dweck, 2010).

In order for learners to be optimally motivated to learn, they must believe that they first possess the skills and competencies to accomplish the learning goals (McCombs, 1991). If they are stuck in this fixed mindset, they are thus unlikely to be able to progress in their learning trajectory. Furthermore, with this fixed mindset, it was found that learners were unable to take feedback from one piece of work and apply it to the next, or to see how skills practiced in one area could be of use somewhere else (Blake, Wass and Walmsley, 2011). My Learning Essentials is designed, in part, to see if the answer to this struggle, on the part of both students and staff, could be addressed by explicit skills training that pushes the skills addressed from the degree programme into the wider world and beyond a single assignment. It is hoped that by removing the official 'place' for an expert in the learning environment, and thus the assumption that no progress can be made without such an expert, that students can be pushed into a growth mindset and begin proactively working to improve and progress. Such an approach also aims to encourage lifelong learning, by empowering the learner, and helping them to develop the autonomy and growth mindset that are essential for learning to continue to occur outside of formal settings.

\section{Report}

The MLE focuses on training that actively emphasises both the transferable nature of the skills supported, and innovative content that introduces students to a wide range of best practice from across the University. A component of the impetus for the creation of the open programme was a growing awareness of the potential inherent in developing a skills support provision that encouraged cross-university collaboration and incorporated strategies that highlight the transferable nature of skills in the design. This exposes students to teaching and best practice from outside their own discipline, whilst working to push participants from a fixed mindset, where assessments and work is seen as siloed, and individual judgements to a growth mindset, where skills can be improved from effort, practice and application (Merriam and Leahy, 2005, O'Rourke et al., 2014)

Designed to work in collaboration with other support on offer, and to bring in partners to highlight expertise and best practice, the sessions focus on the students learning across the subjects and disciplines that they may 
engage in on a daily basis, whilst opening up the learning experience to incorporate students in different years, areas of study and abilities. The sessions follow a common methodology, requiring facilitative structure and focussing on continued personal development. We seek to 'flip' the focus from content, whether it is information literacy or time management, to interactive exploration and experience. In these workshops, there may be less time, quantitatively, spent on specific content but we anticipate, and hope to investigate further, its potential for greater engagement and longterm impact. This facilitative focus frees the trainer from the role of expert and leads to the creation of innovative learning opportunities. Both participant and trainer are required to engage in the learning, changing the dynamic from one of the student-as-vessel-for-expertise to one that demands an equal contribution from both parties. By structuring the workshops, and the programme itself, to require interactivity and engagement, it taps directly into current thought on effort and extrinsic motivation, asking everyone to clarify and work toward progressive improvement. It creates a place where students learn from each other and about themselves, a place where the participants may begin from a different place of expertise, but where everyone seeks to improve.

One of the key sets of workshops on the open training programme is the 'Essential Research Skills' series. These workshops focus on the skills that are necessary to be a critical and successful researcher including: critical thinking, communicating ideas, argument construction, and project management. Following the remit of the MLE open training programme, these sessions are open to all students at the University: undergraduate, post-graduate research, and post-graduate taught, staff are also welcome to attend. There is no distinction made between degree programmes, nor are the sessions levelled beyond a description of the intended learning objectives. Participants in the sessions broadly reflect the demographics found across the University of Manchester and students from all year groups and degree programmes take part in My Learning Essentials. Sessions are not labelled introductory or advanced; instead, participants are asked to read a description of the session and select those that apply to skills they are looking to improve. This creates a group of participants that have the same goal-improving a particular area, but multiple ways of approaching the goal - instead of being limited to one 'right' way, presented by the expert at the front of the room. As stated earlier, participants in My Learning Essentials broadly reflect the demographics present at the University of Manchester, the largest single-site university in the United Kingdom. (Manchester, 2014) It is important to note that, a year into the programme, over $95 \%$ of students who responded to the surveys requesting feedback on their experience in the workshops commented that they were 'at the right level'. In addition to the responses on the level and utility of the sessions, students have stated in the free text session of the survey that workshops were: 
Very enthusiastic presentation, very student- friendly and focused

Excellent session, very informative well planned and at the correct level - good audience engagement and support offered. (feedback surveys, 2013)

The implication here (i.e. that when students are invited to engage and create their own learning experiences, those experiences consistently end up at the correct level for each student's learning) is another area worth noting for further study. If a student is fearful of making a mistake then adequate learning will not take place (Roman and Kay, 2007). The facilitator-led approach aims to empower the students and encourage engagement with both the content and the process. It also aims to show the students that they often have the required knowledge and skillset to achieve a goal; they just need encouragement regarding application, or the chance to explore in a supportive environment.

These sessions are designed to encourage the students to value their own prior knowledge and expertise as they are asked to actively engage and learn cooperatively with the others around them. Instead of the sessions focusing on a trainer delivering the 'answers', or the 'best' way of achieving a goal, the activities and discussion within the workshop emphasise that the expertise, and the answers, are best discovered collectively and with input from all. This design was deliberately chosen in order to help foster a positive and focused-growth mindset on the part of the participants, with the focus on the possibility of improvement, not the achievement of perfection. These goals are framed with the skills presented in order to give the participants a real life focus for improvement, to help support them during their time at university, and to encourage further learning. In addition, because the emphasis is on explicitly linking the skills to personal development, this frees the trainers to present the skills via a variety of innovative and exciting content; from a focus on drama to considering the rich cultural resources of the city, students are exposed to new ways of thinking, while still developing the core skills training to help them succeed.

These workshops focus on the skillset used by researchers to run successful projects and experiments. However, these skills are facilitated not by case studies that tell students what the skills 'should' look like, but activities that explore and improve the skills themselves. As the sessions are open to all students, there is the opportunity for inter-disciplinary collaboration-which highlights the universal nature of the skills being supported. This then encourages students to answer the question of "what next' - that normally impedes the take-up of feedback in many cases - by understanding what the skills can be used for in a variety of areas and practising them within the workshop itself (Hattie and Timperley, 2007). 
Finally, it encourages the participants to apply what they have learnt, and continue on their learning journey, by underlining the progress made and the potential for continued improvement - as they no longer 'need' an expert to guarantee their learning, they can now look to themselves to continue the process.

The activities in these sessions might range from students working in groups to create objects out of modelling clay, to drama exercises designed to unlock their own unique and discernible voices, to brainstorming potential solutions to climate change. These activities ask students to begin by understanding what their confidence in an area may be and then are followed by a second assessment, where students look at what might have improved during the session. This second assessment is key as it both gives the students a concrete measure of where they have improved (thus focusing on a growth mindset) and highlights the skills learned. No longer required to intuit what they were 'meant' to have gotten out of a session, the students can now feel confident in what they have gained and where they might improve in the future, pushing them towards seeing learning as a lifelong process, not a modular series of assessed events.

As the students take part in the workshop and generate their own understanding of the skills covered, they begin to take over the role of expert in the area. As the learning is focusing on the community discovering their own experiences, each of these workshops make sure that there is time for the students to explicitly share their own opinions and knowledge, thereby reinforcing the group-learning, and the ability to learn in the light of one's own experience. For example, when delivering a session on Time Management, the facilitator creates a list of 'Top Tips for Time Management', selected from literature on the subject. In every instance that this session has been run, the top tips brainstormed by the group are almost identical to the list has previously been produced. This approach lends further credence to the notion that the participants have the required knowledge, they just need encouragement on how to apply it.

\section{Discussion}

This methodology is limited in a number of ways, some of which we are currently trying to address. Although every effort is made to get students engaged and participating, there is still often an expectation that students attending a workshop will be told the 'best' way to write an academic paper, deliver a presentation or think critically. Sometimes students are frustrated not to have been given an answer, but instead what could quite easily be viewed as more work - an assumption that they will need to spend a lifetime improving a skill. We hope that, by using strategies such as asking students to create the agenda for the session, we deliberately engage the students in a discussion of what should occur in the sessions, asking them to build the agenda as a group and therefore share both responsibility and understanding 
of what will occur. With agenda building as a common experience, we are at least aligning their expectations with the intent of the sessions. This common agenda building is also crucial in helping to develop autonomy, and ultimately to encourage further learning.

However, it can still be difficult to deliver facilitative, activity-focused workshops when previous systems have developed an inherent demand in the participants for more focused and didactic support. In addition to the struggles of the students, this facilitative and flexible model can be difficult for the trainers. Much of the authority that comes with being the expert in the room is absent in the facilitative model, and the demands on a trainer can be greater when facilitating than when delivering a more standard lecture presentation. Both participants and trainers must engage at a different level when dealing with the activities and the learning objectives. In addition, although the demands that the trainer be a content expert are lessened, they must still deliver a session where the content has been looked at by an expert and deliver activities that fit in with that content and the learning objectives, something that is not always within the comfort zone of skills support.

Finally, the model followed in the open training programme is limited in terms of the number of students that can be addressed in face-to-face sessions. With nearly 40,000 students at the University, MLE could not deliver sufficient workshops to allow for access to all of them. However, because we have decided to follow a blended model, those workshops which are in highest demand are converted into online resources, allowing students to access them from anywhere on campus whenever they need the support. These online resources are not replications of what goes on in the workshops, but instead again focus on delivering the skills support using the interactive and creative possibilities of the medium. This pairing of face-toface and online sessions allows the MLE to deliver skills support at the point of need while still maintaining the small groups and facilitative model that are key to the skills offer. This facilitative model does not focus on sending students away experts in a content area, a skillset, or a method. Instead it focuses on identifying areas for improvement and the steps that are necessary in order to achieve that goal, demanding student engagement instead of highlighting trainer expertise. It also aims to empower the student to find out more about the subject area, either through personal study or continual professional development.

The Essential Research Skills, along with all of the resources, emphasises learning in a supportive and creative environment, one where students are valued for the expertise they bring, and in which a community is formed pursuing a common goal. Thus, we are not only supporting the participants needs in skills support but also in developing a community of learners to draw upon and learn from, democratising the process and allowing for further transparency in what is possible for learners. In order to ensure that 
students are comfortable with this model, the trainer deliberately follows a facilitative structure, encouraging students to contribute to the final strategies and skills developed and to recognise their own abilities and potential for improvement. With this model, the student's awareness of the potential and transferable nature of the skills comes from being a part of their identification. This model is one that, from initial surveys and conversations, shows much promise in being one answer to the questions students face, and universities must answer, around getting the most out of educational opportunities at university and learning skills for the future. The facilitative methodology takes positive steps towards student independent, not isolated, learning and creating engaged and self-starting participants. Because they are active participants in the activities of the workshop and helping to design the strategies that support their skills, students attending the workshops are better able to identify both where they need to improve and, crucially, the steps required in order to achieve that improvement.

From the experiences of the MLE programme, there are three clear pieces of good practice that we offer as recommendations for encouraging lifelong learning in student-centred learning environments:

1. Allow the participants to help construct the taught programme. Having a set of learning objectives is good for an initial structure, but it is important to be flexible enough to respond to the needs of the group, and to demonstrate that learning can be an organic process, which they can tailor to their individual needs.

2. Ensure that the participants are presented with opportunities to assume the role of the 'expert'. For example, encourage the sharing of anecdotal evidence of best practice.

3. Guide the participants in their understanding that sometimes there is no one singular 'best' answer, and that temporary 'failure' is a necessary step in searching for the solution that is most suited to their own individual needs.

These types of student-centred learning experiences offer the participants a wonderful opportunity to explore in an interactive and interdisciplinary environment. Providing the students with a physical space in a relatively informal setting, as well as encouraging a growth mindset and stimulating intellectual curiosity, will ultimately provide them with the skills and motivation to continue their journey beyond higher education and into further lifelong learning opportunities.

\section{References}


Blake, J., Wass, V., Clift, P. \& Walmsley, L. (2010) Self Portraits and Perpetual Motion: The Student Experience of Informed Choice and Feedback. European Learning Styles Information Network.

Blake, J., Wass, V. \& Walmsley, L. (2011)' Inertia and the Learning Journey: Choice, Resources, and the Student Experience.' Education, Learning, Styles, Individual Differences Network (ELSIN), XVI: 57-65.

Collins, J. (2004) 'Education techniques for lifelong learning: Principles of adult learning.' Radiographics, 24, 5: 1483-1489.

Dweck, C. (2006) Mindset: The new psychology of success, New York: Random House.

Dweck, C. (2010) 'Even geniuses work hard.' Educational Leadership, 68, 1: 1620.

Fischer, G. (1999) Lifelong learning: Changing mindsets. Proceedings of ICCE, $7^{\text {th }}$ International Conference on Computers in Education, Chiba, Japan, $4^{\text {th }}-7^{\text {th }}$ November 1999

Goodyear, P. (2000) 'Environments for lifelong learning.' In Michael Spector and Theresa Anderson (ed.) Integrated and holistic perspectives on learning, instruction and technology. New York: Springer.

Hattie, J. \& Timperley, H. 2007. The power of feedback. Review of educational research, 77, 81-112.

Huang, H.-M. (2002) 'Toward constructivism for adult learners in online learning environments.' British Journal of Educational Technology, 33, 1: 27-37.

Jonassen, D. \& Land, S. (2012) Theoretical foundations of learning environments, New York: Routledge.

Jones, R.(2013) 'Alan Gilbert Learning Commons University of Manchester.' SCONUL Focus, 57: 14-16.

Jones, R. \& Blake, J. (2013) Skills Development at the University of Manchester Library. SCONUL Focus, 58: 35-36.

The University of Manchester (2014) 'Facts and figures | The University of Manchester. Facts and Figures' Available from: http://www.manchester.ac.uk/discover/facts-figures/ (Accessed 12 ${ }^{\text {th }}$ March 2015)

McCombs, B. L. (1991) 'Motivation and lifelong learning', Educational psychologist, 26, 2: 117-127.

Marjanovic, O. \& Bandara, W. (2011) 'The current state of BPM education in Australia: Teaching and research challenges.' in Michael Muehlen and Jianwen Su (eds.) Business Process Management Workshops, New York: Springer

Merriam, S. B. \& Leahy, B. (2005). Learning transfer: A review of the research in adult education and training. PAACE Journal of lifelong learning, 14: 1-24. 
O'Rourke, E., Haimovitz, C., Ballwebber, C., Dweck, C. \& Popović, Z. (2014) Brain points: a growth mindset incentive structure boosts persistence in an educational game. Proceedings of the 32nd annual ACM conference on Human factors in computing systems, Toronto: Canada April $26^{\text {th }}-$ May $1^{\text {st }}$ 2014.

Roman, B. \& Kay, J. (2007). 'Fostering curiosity: Using the educator-learner relationship to promote a facilitative learning environment.' Psychiatry: Interpersonal and Biological Processes, 70,3: 205-208.

Sharples, M. (2000). The design of personal mobile technologies for lifelong learning. Computers \& Education, 34, 3-4: 177-193.

Smith, F. (2014). To think: In language, learning and education, Oxon: Routledge. 